\title{
A place to study, a place to pray Supporting student spiritual needs in academic libraries
}

$\mathbf{H}^{2}$ ave you stumbled across a student using a tucked-away space in your library to pray? Maybe library staff have seen students using a study carrel, a stairway, or even the stacks. Perhaps students requested a space within the library to use for prayer or meditation, and now you provide a permanent space.

At the Penn State-Harrisburg and Abington Libraries, we've witnessed students practicing their spirituality with whatever space is available or convenient. Through conversations with librarians at other Penn State campuses and at libraries across the United States, we discovered that our experiences were more common than we anticipated, regardless of the religious or secular status of the school. A number of academic libraries have transformed library spaces into areas for various spiritual practices to create a welcoming environment for all students, embarking into new usercentered territory.

In support of a user-centered focus, we believe that preserving the dignity and affirming the value of our students is critical in times of change and uncertainty in higher education. As part of a commitment to respecting and supporting students of all backgrounds and in recognition of the students' spiritual well-being, we encourage academic librarians to consider student use of library space for spiritual practice and work with their student community to better understand their needs for a place to pray.

\section{Shouldn't this be in the student union? Using a library space for prayer} It may seem unusual for students to seek a prayer space in the library. But consider its position: it is often centrally located, it typically has the longest hours of any campus building, and students may spend a great deal of time there. These factors make the library a safe, convenient spot to pray without suffering much disruption to academic activities. In addition, a somewhat-private and quiet place to pray is easily found, be it at a carrel, between the stacks, or in a study room. These spaces may not be officially designated for prayer, but they are frequently available for short-term student use. Some academic libraries have formally created spaces or repurposed study rooms for students who need a quiet space to carry out religious practice, or who would like to just sit silently for a period of time. Our conversations with librarians indicated that even at libraries without a designated space, staff found students praying in stairwells, hallways, bathrooms, study rooms, and other secluded parts of the library.

Guidelines and standards from both ALA and ACRL do not prohibit, and in fact encour-

\footnotetext{
Emily Mross is the business librarian and outreach coordinator at Penn State-Harrisburg Library, email: elm43@psu.edu, and Christina Riehman-Murphy is a reference and instruction librarian and outreach coordinator at Penn State-Abington Library, email: cer20@psu.edu
}

(C) 2018 Emily Mross and Christina Riehman-Murphy 
age, the support of patrons' religious lives within the confines of fair and equitable community services to all. ALA Intellectual Freedom resources indicate that there is nothing illegal or inappropriate about accommodating the religious needs of patrons, so long as the accommodations do not violate any previously established library policies. ${ }^{1}$ Therefore, students should not be barred from using a library space for a religious purpose, like a brief prayer time, if it is not disruptive to others. Additionally, ACRL Diversity Standard Four calls for libraries to be inclusive to all patrons in programs and services. ${ }^{2}$ Providing a quiet space for prayer, meditation, and reflection can certainly be viewed as an inclusive service that makes students feel welcome and valued in the library.

\section{Penn State-}

\section{Harrisburg Library}

Penn State-Harrisburg library created a prayer space in 2014 in response to student needs. Previously, library staff accommodated students in their offices or in the library archives reading room during prayer times. Demand increased steadily, and the need for a designated space became apparent. The space was tucked in a small corner of the library administrative suite previously used as a staff locker area. A door, equipped with an in-use/not in use sign, provided the enclosure with some privacy. Praying students flipped a sign affixed to the door during prayer. When the space was occupied, staff walked around the suite, rather than through it. The space was almost exclusively used by Muslim students and was only large enough for individual prayer. It contained a chair for removing shoes and an Islamic prayer rug. Though the prayer space lacked complete privacy or washing facilities, it was an improvement on previous ad hoc spaces.

No statistics were kept on the use of the library's prayer room to protect privacy, however, it was frequently occupied during casual observations, despite no advertisement of the space. Though the space was not perfect, we attribute its heavy use to the library's long daily hours and its role as a student hub.

In summer 2016, a new student center opened that includes an interfaith spiritual center providing adaptable spaces for congregational prayer, as well individual prayer spaces with privacy curtains and washing stations. With the addition of the spiritual center, the library prayer space was decommissioned. Students are still occasionally found praying in the space, and the prayer rug remains in the room. Students have also been observed praying in other areas of the library. Students praying in the library are not disturbed or redirected to the spiritual center.

\section{Penn State-Abington Library}

The Penn State-Abington campus does not currently have space dedicated to interfaith activities or religious groups, but for many years, faculty and staff have informally accommodated students' spiritual needs in a variety of ways. Student life staff who work closely with campus groups have made their offices available for students who need a prayer space, and students freely use the library stacks for prayer. Muslim students use the space frequently, as the bookshelves provide a quiet, semi-private space 
that faces east. Abington students are able to pray while conveniently staying in their study areas, and staff are careful not to interrupt students while they pray. Though there is discussion of creating a suitable campus prayer room, due to space constraints, it is not possible to provide a designated, enclosed prayer space in the library.

\section{Prayer spaces at other campuses}

At present, designated spiritual spaces are available at four Penn State University Libraries locations across the Commonwealth. Penn State Law Library provides an enclosed space for students conducting private, personal activities, such as prayer or nursing/ lactation. The H. Laddie Montague Jr. Law Library at Dickinson Law enclosed a previously open alcove just outside the library, outfitting it with a comfortable chair, a rug, and spiritual texts. The Berks Campus provides a repurposed study room for prayer and meditation, and the Hazelton Campus created a meditation corner within the main library area.

Penn State is not unique in providing these spaces. A simple web search reveals that libraries at North Carolina State University, ${ }^{3}$ the University of Wisconsin-Madison, ${ }^{4}$ and Duke University ${ }^{5}$ have all created spaces for prayer, meditation, or reflection. We conducted a large-scale survey on library prayer spaces in spring 2017. Preliminary data reveals many academic library professionals observe similar prayer space usage in their own libraries. In response, they are allocating spaces for students' spiritual practices. Among library staff respondents to our survey, $51 \%$ reported observing students using the library as a prayer space, and 50\% reported that their academic library currently provides or previously provided a prayer space.

\section{Getting started with your space}

We experienced students using the library informally as prayer spaces. It is possible the same occurs in your library, although it is possible neither library staff nor cam- pus administration would necessarily be aware of students engaged in silent prayer or meditation. If you have not personally witnessed prayer in the library, talk with library staff and student services to discuss potential campus needs. Like Abington Library, you may not have room to make a formal space, perhaps you cannot determine a large enough need for one. In these instances, consider implementing policies or guidelines that help create a culture of respect and dignity for students who informally use library areas for prayer and meditation. In alignment with the ACRL Diversity Standard 10, staff training on diversity and inclusion should include strategies for providing services responsive to religious backgrounds, which could include accommodating spiritual practices within the library, regardless of the existence of a designated prayer space. ${ }^{6}$

If your library creates a formal prayer space, know that it does not necessarily take much to make a welcoming and inclusive area for all faiths and practices. Prayer and meditation rooms in other libraries are often repurposed small group study rooms. Spaces generally include a chair for removing shoes or simply for sitting. Consider surveying students to determine the best features for the space. Campus student religious groups may be able to provide items that are appropriate to their spiritual practices, such as a prayer rug for Muslim students or floor cushions for meditation practices. Some libraries have gathered religious and spiritual texts from their collections and placed them on a bookshelf located near the room for students who may wish to refer to them. Walls are best kept to a neutral color and left blank because it is important avoid portraits or iconography. Anything beyond these items is not needed for a basic prayer or meditation space.

A helpful guide for academic libraries looking to create an interfaith campus space is available from Interfaith Youth Core, which partners with diverse public and private college campuses to build interfaith cooperation. ${ }^{?}$ 


\section{Conclusion}

Religious activities on campus are as diverse as our students. The library can respect the spiritual needs of students without a great deal of sacrifice. Consult with campus stakeholders and determine if there is a need for a formal or informal space in your library or on your campus. Follow up with professional development to ensure respect, equity, and inclusion are part of your library culture. By providing formal or informal, flexible and inclusive spaces for spiritual practices, we facilitate an environment of inclusion and affirm a sense of belonging. In this way, academic libraries can help contribute to a culture of student support, and therefore, success.

\section{Notes}

1. ALA, "Religion in American Libraries," accessed August 3, 2017, www.ala.org /advocacy/intfreedom/religionfaq.

2. ACRL, "Diversity Standards: Cultural
Competency for Academic Libraries," accessed August 3, 2017, www.ala.org/acrl /standards/diversity.

3. North Carolina State University Office for Institutional Equity and Diversity, "Interfaith Prayer and Meditation Spaces," accessed December 20, 2017, https://oied.ncsu.edu /divweb/interfaith-prayer-and-meditationspaces/.

4. University of Wisconsin-Madison Libraries, "Reflection Space," accessed December 20, 2017, https://www.library.wisc.edu/ college/spaces/reflection-space/.

5. Duke University Libraries, "Prayer and Meditation Space," accessed December 20, 2017, https://library.duke.edu/using /policies/prayer-and-meditation-room.

6. ACRL, "Diversity Standards: Cultural Competency for Academic Libraries."

7. Interfaith Youth Core, "Creating an Interfaith Room or Space on Campus," accessed August 3, 2017, www.ifyc.org/sites/default /files/u4/Interfaith-Space.pdf. ュ

("Who's left out . . ." continues from page 320)

\section{Conclusion}

We wonder why students do not understand the idea that scholarship is a conversation, though we are effectively telling them that they are not a part of it by insisting that it looks a specific way. It is important that we acknowledge that students do participate in the scholarly conversation through their coursework and in their own interactions, despite the fact that it is often not recognized as scholarly because of the form and forum in which it takes place. Many students will, at some point, need to learn to write in a style and format that is more recognizable to academia, but acknowledging that they are already having scholarly conversations gives us a way to connect their experience with the academic one. We can also help students by talking with them about the complex information world we live in and encouraging them to be critical and skeptical of all information, including journal articles. By acknowledging there are places outside of journals in which one can find reliable and relevant information, we can help students not only understand the scholarly conversation, but also help them participate in it.

\section{Notes}

1. ACRL, "Framework for Information Literacy for Higher Education," February 9, 2015, www.ala.org/acrl/standards /ilframework.

2. Amy Mitchell, Jeffrey Gottfried, Michael Barthel, and Elisa Shearer, "The Modern News (continues on page 336) 